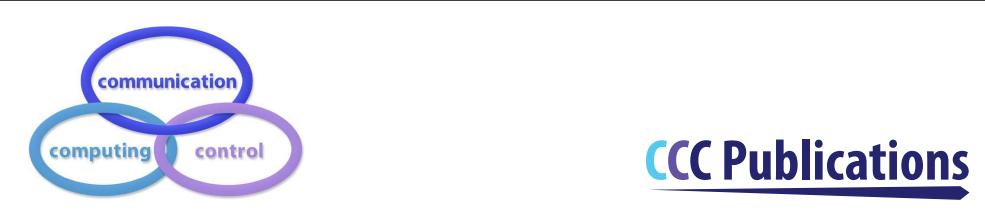

\title{
A Fuzzy Bayesian Network Model for Quality Control in O2O e-Commerce
}

\author{
H. Zhang, H. Feng, Y. Cui, Y. Wang
}

\author{
Hao Zhang* \\ Logistics Management Department \\ Beijing Technology and Business University, China \\ *Corresponding author: zhhaozhhao@126.com

\section{Huixia Feng} \\ Logistics Management Department \\ Beijing Technology and Business University, China \\ fenghuixia2019@163.com \\ Yan Cui \\ Logistics Management Department \\ Beijing Technology and Business University, China \\ cui82986637@163.com

\section{Yuting Wang} \\ Logistics Management Department \\ Beijing Technology and Business University, China \\ firstyuting@gmail.com
}

\begin{abstract}
With the popularization of the online to offline $(\mathrm{O} 2 \mathrm{O})$ e-commerce on fresh food products, how to control the quality is becoming increasingly important. To adequately address this problem, this paper presents a fuzzy Bayesian network model for effectively controlling the quality in O2O ecommerce. Reasoning about uncertain events and incomplete data through an intelligent simulation with Bayesian networks provides a convenient and fast method of evaluation and analysis for ecommerce platforms to quickly select fresh food suppliers. Such a model is capable of appropriately modelling the uncertainty inherent in the fresh food product distribution process. It focuses on the identification of the critical factors that affect the food product quality along the supply chain. This leads to the development of a complete selection and evaluation system for the quality in $\mathrm{O} 2 \mathrm{O}$ e-commerce. A simulation study is conducted that shows the proposed model is applicable for effectively controlling the quality in $\mathrm{O} 2 \mathrm{O}$ e-commerce. Ultimately, the unloading level, warehouse inspection and warehouse monitoring are determined as the entry points for quality control, with corresponding degrees of influence of $44 \%, 37 \%$, and $34 \%$. The main points to protect the quality of food are introduced, which provides a theoretical basis for solving fresh food safety problems for business platforms.
\end{abstract}

Keywords: fresh food quality control; O2O mode; fuzzy Bayesian network; triangular fuzzy numbers. 


\section{Introduction}

Online-to-offline $(\mathrm{O} 2 \mathrm{O})$ commerce is a new type of e-commerce that has emerged in recent years. It involves in an organic combination of online channels and offline channels for selling various products in the marketplace. $\mathrm{O} 2 \mathrm{O}$ commerce makes the connection between online and offline more closely. This provides a new opportunity for the development of various industries and pushes the development of e-commerce to a higher level. The $\mathrm{O} 2 \mathrm{O}$ commerce relies on advanced mobile Internet technologies with the integration of online platforms with offline entities. It can use online platforms to introduce customers who often shop online to offline stores and let them feel the product in person. More importantly it can use publicity and good services of offline physical stores to achieve good brand awareness, and then use online promotions to attract customers to return to online consumption, and ultimately reach the maximum benefit. It is a kind of business model in which carry out bidirectional drainage and cross development between online and offline. The benefit of the $\mathrm{O} 2 \mathrm{O}$ model is that it provides a localization services with the combination of online and offline to more effectively promote corporate values and services. The integration of online payment methods and traffic, with the help of data that can be monitored, continues to carry out customer relationship management in a continuous manner so as to conduct accurate marketing. In addition, the $\mathrm{O} 2 \mathrm{O}$ model reduces intermediate links and greatly reduces logistics costs.

With the development of $\mathrm{O} 2 \mathrm{O}$ commerce in recent years, there is an increasing use of the $\mathrm{O} 2 \mathrm{O}$ commerce for fresh food products including fresh vegetables, fruits, meat and seafood. There are several major $\mathrm{O} 2 \mathrm{O}$ commerce platforms including Yihaodian, Amazon China, and Jingdong Mall that have launched online fresh food business in China. In 2015, the transaction volume in China's fresh O2O commerce market reached 49.71 billion yuan. In 2017, the transaction volume of China's fresh $\mathrm{O} 2 \mathrm{O}$ commerce market exceeded 100 billion yuan. This shows that there is a huge potential for the fresh food product market in $\mathrm{O} 2 \mathrm{O}$ commerce in China.

As people are increasingly pursuing high quality in their lives, fresh produce occupies an increasingly important place in the human food supply because of health-promoting nutritional properties. Considering the special properties of fresh food, factors that affect the quality of fresh food are also more complicated due to many links related to the supply of fresh food under the $\mathrm{O} 2 \mathrm{O}$ mode. Therefore, it is of great importance and a challenge to accurately judge the factors that have impact on the quality of fresh food. Fresh food has been found to contain Listeria spp..There has been an increase in foodborne outbreaks and cases associated with fresh produce, but data in the literature on the prevalence of pathogen contamination are inconsistent [5]. Dong et al. pointed out the technical difficulties and solutions to carrying out the quantitative risk assessment of food microorganisms and discussed the application prospects [9]. Lei Yang developed a fresh product supply chain under O2O and freshness-keeping decisions are investigated [30]. In addition, food authenticity issues such as the illegal substitution of frozen meats for fresh meats constitute one of the public concerns among food authorities, industry, and consumer groups. An enzymatic method based on the activity of beta-hydroxyacyl-CoA-dehydrogenase was used to differentiate between fresh/chilled and frozen pork meats [6]. To strengthen the quality and safety management of fresh food, a farm food safety-risk assessment tool has become popular, as it serves as a self-assessment and educational tool for fresh produce farms to evaluate their food safety practices [23]. An inter-organizational information system has been applied to the IOIS architecture for the traceability of fresh vegetables [1,26]. A previous study examined the key drivers and constraints for implementing traceability [20]. Zhang et al. elaborate the role and existing problems in the food safety from the perspective of enterprises, government and regulatory power of third parties [32]. Akshit Singh et al. propose a big-data analytics-based approach and inform supply-chain decision makers about quality of food products [22].

There are various attempts in the development of specific approaches for tackling the factors influencing the quality of fresh product in different circumstances. Due to the uncertainty and the risk is not easy to quantify, Davidson et al. defined the initial hazard level of the food supply chain system and the potential changes in circulation operations. Then, the fuzzy comprehensive evaluation method was used to evaluate the early risk of the system and to quantify or classify the fuzzy values of the evaluation output [8] Xu et al. solved the single-plant location decision problem and the multiple location decision problem [28]. Martínezsimarro et al. studied the relationship between food quality 
and safety and the reality of enterprises by using fuzzy neural theory and established a evaluation model [21]. However, the above studies have not recognized the risk from the aspect of factors, Belc et al. used the Delphi method to identify the quality and safety risk factors [4]. However, the existing methods for controlling the quality of fresh food products can not find precisely the relationship between factors and make reasonable reasoning. Their application are scattered without organization and systems that can fully integrated complete information in the fresh food supply process in the $\mathrm{O} 2 \mathrm{O}$ mode and fundamentally solve the problem of quality and safety. In addition, the methodology used lacks objectivity and does not adequately quantify the problem.

This paper sort out the key factors influencing the quality control of fresh food and integrate a system of fresh food quality indicators to provide an entry point for quality control using fuzzy Bayesian network that combines triangular fuzzy numbers [10] and Bayesian network based on the analysis of the supply of fresh food. This method overcomes shortcomings of the fault tree analysis, risk matrix method and other evaluation methods in visually describing the abstract problem and achieves reasonable reasoning of data that can not be quantified .

This paper is organized as follows: Section 2 presents the fresh food supply in the O2O model. Section 3 provides details of the fuzzy Bayesian network model. Section 4 presents the simulation study. Based on the simulation results in Section 5, this paper discusses the direction and standards for fresh food quality control. Finally, the conclusions are presented in Section 6 .

\section{$2 \quad$ Fresh food supply in $\mathrm{O} 2 \mathrm{O}$ commerce}

At present, e-commerce is becoming more and more popular. Fadwa Chalfoun et al. analyzed Electronic Media importance and prepared classification of E-media [11]. At the same time, Aurelija et al. discussed general trends of online shopping and the consumer protection [2]. In the context of e-commerce, we need to make various decisions. Xu et al. provided more choices for decision-making and obtained a universal decision model [29].

The storage condition and cold chain structure are important factors influencing fresh food quality The smart freezing technology enables real-time monitoring of quality during the freezing process and helps improve the product quality and freezing efficiency [17, 25]. Supercooling is also a foodprocessing technique with the potential to significantly increase the shelf life of foods [24]. However, the loss of fresh food in the transportation process is serious because it is perishable [16]. We must perfect the logistics of the transportation of fresh food and decrease the loss rate of fresh food in the transportation process [34]. Based on fresh food e-commerce enterprises, a forward and reverse logistics network and route planning in the environment of low carbon emissions are established [14]. Zou pointed the safety reliability of fresh food cold chain logistics [35] Xin et al. use an Euler algorithm to optimize the flow patterns in a perishable food supply chain network [27].

Because of the increase in consumers' awareness of fresh foods, food packaging material is important for food safety. The demand for packaging materials is no longer limited to ordinary materials but has gradually changed into safe, healthy and efficient materials [12]. Modified atmosphere packaging can become one of the most appropriate technologies for packaging fresh and fresh-cut produce to extend the shelf life of fresh produce and provide a high-quality product $[3,19,33]$. However, fresh food cannot be sterilized by heat, so a sterilization method using cold plasma for packaged fresh food was proposed [15]. In addition, the behaviours of retail and food service employees regarding food safety for fresh and fresh-cut produce are often associated with food illness outbreaks, so it is important to identify the factors influencing employees' practices [7]. So, it is important to link data sharing with the sustainability performance of the entire fresh food supply chain, and it is not considering only one aspect [18].

Fresh food supply analysis in the $\mathrm{O} 2 \mathrm{O}$ mode aims to clarify the factors affecting fresh food quality in the supply process. By dividing the supply chain in detail and clearly analysing the specific operation processes, the quality and safety factors involved in the supply chain such as stocking, distribution and processing, tallying and distribution are clarified, and the unloading level, warehouse inspection and other key influencing the quality of food factors are extracted. This article sorts out fresh food supply operation processes in the $\mathrm{O} 2 \mathrm{O}$ mode based on expert consultation and field research, as shown 
in Fig. 1.

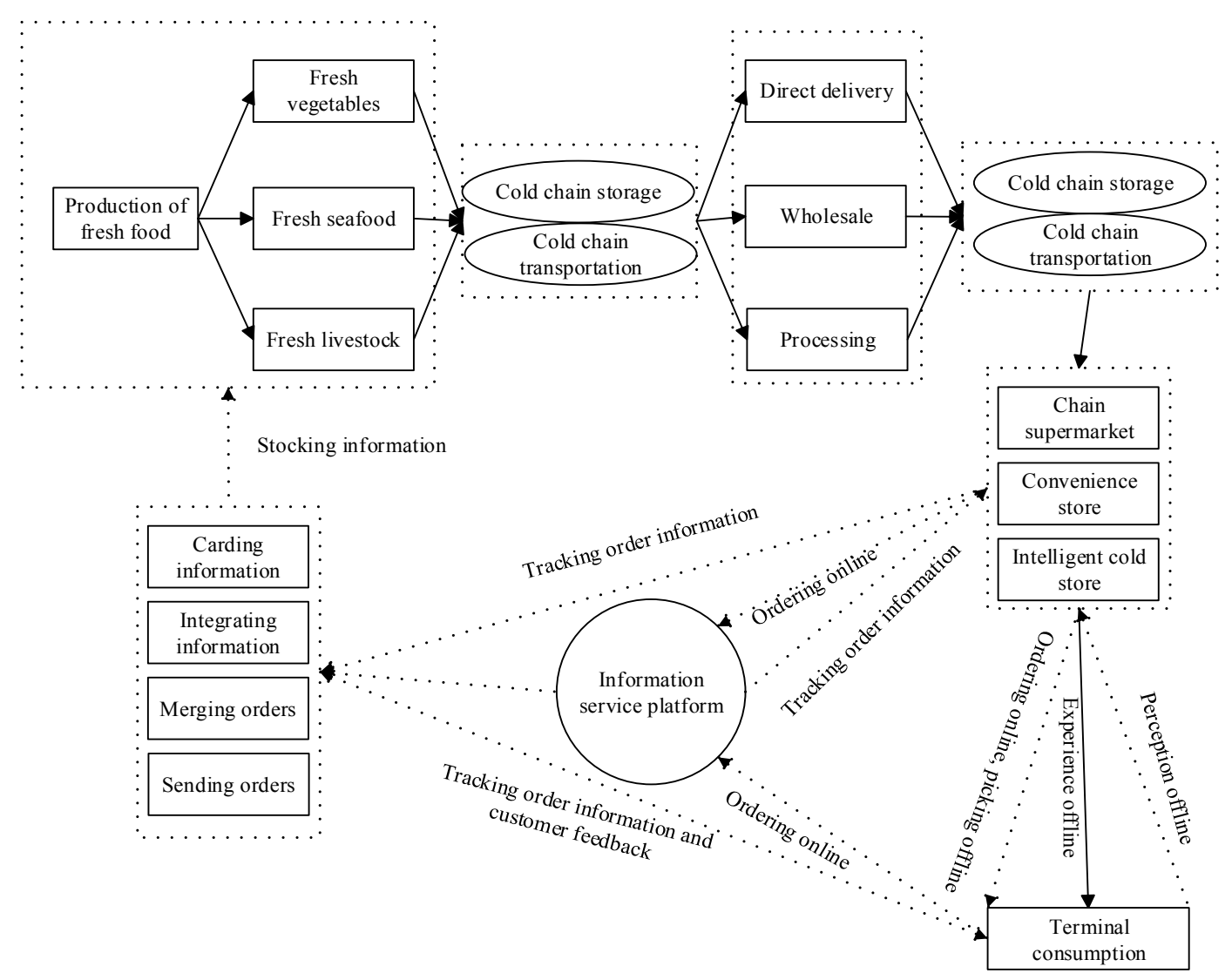

Figure 1: Supply process for fresh food in the $\mathrm{O} 2 \mathrm{O}$ mode

This study focuses on the process from chain supermarkets and convenience stores to consumer terminals. Large supermarkets and fresh merchants under $\mathrm{O} 2 \mathrm{O}$ act in accordance with customer demand forecasts and purchase plans in conducting procurement; then, they receive the goods for acceptance, storage, food information registration and classification. Considering the special nature of some fresh food, businesses must also carry out food circulation processing to extend the shelf life or increase its added value. After the customer's new order is received, to satisfy the customer's order requirements, the fresh food is sorted, picked, packaged, etc., and is moved to the waiting area. To ensure the efficient delivery and quality safety of fresh food, by making delivery plans and specifying the delivery route, the merchants send the delivery notice to the customer, load the goods into the refrigerated distribution vehicles, and control the temperature during the transport process until the fresh food is safely served to customers.

The analysis of the factors influencing fresh food quality is the basis and standard for quality inspection in the $\mathrm{O} 2 \mathrm{O}$ mode. This comprehensive system reflects different attributes of the complex system of fresh food enterprises and the environment in the $\mathrm{O} 2 \mathrm{O}$ mode and provides a direct basis and entry point for quality control. So, a scientific and completely comprehensive analysis and evaluation system must be established. Considering the needs and requirements of consumers in combination with the attributes and characteristics of fresh food supply links in the $\mathrm{O} 2 \mathrm{O}$ model, this paper analyses and establishes a comprehensive evaluation index system of fresh food quality from the preparation, circulation processing, tally, and delivery links to clarify all factors in the supply links, as shown in Table 1.

\subsection{Preparation for goods}

Preparation for goods include purchase and storage. Purchase is the fresh food from the upstream to accept the goods from the truck unloaded, check the number and status of goods. And in accordance with the sorting and picking process requirements, we should do a small amount of storage preparation 
Table 1: The factors influencing the quality of fresh food in each step of the supply chain

\begin{tabular}{cl}
\hline Stages & Factors influencing quality \\
\hline Preparation for goods & $\begin{array}{l}\text { Purchase plan, acceptance inspection, unloading, re- } \\
\text { ceiving, classifying fresh food, inspection in ware- } \\
\text { house, monitoring the warehouse }\end{array}$ \\
Distribution processing & $\begin{array}{l}\text { Picking outbound, cleaning and cutting, packing, } \\
\text { stock-in }\end{array}$ \\
Tally links & Sorting, allocation inspection, outer packaging \\
Delivery links & $\begin{array}{l}\text { Delivery plan, delivery notice, outgoing quality con- } \\
\text { trol, loading, transport logistics, whole-process tem- } \\
\text { perature control, unloading }\end{array}$ \\
\hline
\end{tabular}

in the tally venue.

Reasonable purchase plan to help the supplier make their arrival time be reasonable, or else it will make the supplier too much time to arrive, resulting in the receipt of the scene is very congested, extending the time of fresh food exposed to room temperature. After the arrival of fresh food, if the receiving staff did not follow the standard to the arrival of fresh food for basic visual inspection and vehicle temperature record check, then it may danger the safety of fresh food .

According to the Beijing cold chain market research shows that most of the fresh food packaging damage occurred in the loading and unloading operations process. In the unloading operations, different operating equipment on the quality of fresh food safety and safety of the extent of a great difference. When the traditional manual handling method is used, not only the work efficiency is low, but also the time of exposure of the fresh food to the room temperature is greatly prolonged, and the quality of the freshman is affected by the quality of the personnel. Which will make fresh food packaging damage probability and fresh food itself greatly increased the probability of damage.

In the process of receiving food in the warehouse, this process is carried out in the outdoor temperature, so it may lead to the risk of damage to product quality. Meanwhile, unreasonable fresh food classification operations can infect other food and make fresh food by cross-bacterial infection.

After storaging, if the "quantitative test" errors occur, the quality of fresh food will not be affected. However, if the "quality inspection" errors occur, for example, they can not correctly check out the pesticide residues, hormones and other chemical agents excessive food, which will make these unsafe fresh food into the distribution channels, serious harm to fresh food Quality and safety.

If treasury monitoring operations is unreasonable, it may damage the quality of fresh food from four aspects. First of all, the Treasury temperature monitoring will make fresh food is not conducive to the preservation of the temperature, to speed up the deterioration of fresh food. Second, the Treasury health is not timely clean up, deterioration of fresh food will breed bacteria. Once again, most of the operations are carried out in the warehouse, if the cold storage equipment failure, will make the entire distribution center of fresh food are not conducive to the preservation of the temperature, so that its food safety has been seriously affected. Finally, the Treasury is likely to fire, theft and other accidents, but also may be affected by natural disasters such as the impact of the earthquake, which will be on the distribution center of fresh food quality and safety impact.

According to the analysis of the preparation for goods, the factors affecting the quality of fresh food mainly are divided into purchase plan, acceptance inspection, unloading, receiving, classifying fresh food, inspection in warehouse and monitoring the warehouse.

\subsection{Distribution processing}

Fresh food circulation processing is based on the characteristics of fresh food distribution. Before stocking, we can extend its shelf life, increase the added value and process fresh food.

The process of picking outbound is carried out in the outdoor temperature, there is also a risk of exposure to fresh food and damage to quality and safety. Cleaning and cutting operations are very strict with environmental requirements. The workplace must be disinfected and cleaned in strict 
accordance with national food hygiene requirements and relevant laws and regulations. If the cleaning operation and cutting operation are not clean, the cleaning solvent used does not meet the national health requirements, and the disinfection and cleaning work of cutting equipment is not in place, it will cause damage to the safety and quality of fresh food. If the packaging of fresh food is unreasonable, and it is not sealed or packed in dark box according to the characteristics and requirements of fresh food, it will not only fail to protect the safety of fresh food, but also cause great harm to the safety of fresh food. In addition, due to the negligence of the operators, the packing is not tight or there is leakage, gas, etc., which will also endanger the safety of fresh food. In the process of storage, the quality and safety of fresh food will be affected by outdoor temperature.

Therefore, fresh food quality distribution process will be affected by various interference factors, mainly in the following aspects: picking outbound, cleaning and cutting, packing and stock-in.

\subsection{Tally links}

Tally link is an important part of fresh food distribution. The impact of different equipment on the quality and safety of fresh food is different in sorting operations. The traditional manual sorting operations are inefficient and prone to appear the wrong sorting situation, and if the sorting operations staff quality is low, it will greatly increase the chance of fresh food damage. Allocation inspection is to ensure that fresh food are good quality, if there are inspection errors, resulting in substandard fresh food into the delivery link, which will damage the quality of fresh food.

Therefore, the tally process of each process has different degrees of impact on the quality of fresh food, mainly reflected in the following aspects: sorting, allocation inspection and outer packaging.

\subsection{Delivery links}

Delivery plans mainly include the delivery quantity, object, delivery route and distribution centers location[31], which will impact on the delivery time. If the communication with the customer is not smooth, delivery notice is not timely or delivery of information are wrong, they will enable customers to prepare the goods and the equipment in advance, so that the probability of fresh food damage is reduced after the fresh food arrives at the destination and is unloaded. Shipping inspection errors may lead to fresh food delivery errors, resulting in unnecessary returns to extend the fresh food in the distribution channel within the residence time, thereby affecting the quality of fresh food safety.

The loading process needs to consider the factors that affect the safety of fresh food from two aspects. First of all, different loading equipment has different impact on the quality and safety of fresh food. Secondly, the rationality of fresh food loading will affect the temperature control of fresh food. If the load density is too high, the temperature of the box will be uneven, and if the load density is too low, the refrigerator resources will be wasted. The reasonable loading sequence will also affect the smooth transportation and loading and unloading of fresh food, and the unreasonable loading will extend the transportation time, thus affecting the quality and safety of fresh food.

Transportation logistics includes refrigerated vehicle failure factors and traffic environment factors. In the process of transportation, if the refrigerator car can not fail, it will greatly extend the delivery time of fresh food and increase the probability of deterioration of fresh food. The transportation process of transportation in the transportation environment will also have an impact on fresh food, such as traffic congestion, accidental traffic accidents will cause damage to fresh food.

If the temperature control equipment in the transport process failure, it will make fresh food is not conducive to the preservation of the temperature environment, thereby increasing the chance of fresh food deterioration. Distribution and loading and unloading operations are facing the same problems, but also affected by the quality of fresh food.

The impact of the delivery on the quality of fresh food is mainly reflected in the following operations: delivery plan, delivery notice, outgoing quality control, loading, transport logistics, wholeprocess temperature control and unloading.

The links involved in the supply of fresh food are complex, resulting in interference and difficulty in the evaluation of quality. It is necessary to establish an evaluation system based on the analysis of multiple influencing factors according to the different links and processing flow in the supply process 
to conduct a comprehensive and reasonable fresh food quality evaluation from a variety of aspects so as to effectively manage the quality and safety of fresh food. However, in order to carry out effective quality control of fresh foods, it is necessary to analyse the influence of each factor reasonably, find out the key factors and provide the entry point of quality control so as to reduce the risk of deterioration of fresh food.

\section{The fuzzy Bayesian network model}

To study the key factors influencing the quality control of fresh food in the $\mathrm{O} 2 \mathrm{O}$ mode, a series of factor indicators must be analysed and compared. Because the degree of influence of each factor is difficult to quantify and because of the uncertainty, the fuzzy Bayesian network model combining the Bayesian network and the triangular fuzzy numbers which organically integrates the Bayesian method and graphical theory based on probability uncertainty and statistical theory can be used to achieve forward and reverse complex reasoning. The reasoning results are directly reflected in the network diagram to provide an intuitionistic macroscopic description of the abstract problem domain. The key influencing factors are analysed by examining the probability.

In the forward reasoning, the Bayes network algorithm is based on the joint probability formula to obtain the joint probability distribution of each node. The concrete calculation process is as follows: Suppose that $\mathrm{n}$ nodes in the Bayesian network are represented by $X_{1}, X_{2}, \ldots, X_{n}$. The values of the nodes are represented by small letters. For example, the value of $X_{i}$ is $x_{i}$. For the Bayesian network containing $\mathrm{n}$ nodes, according to the chain rule, the joint probability distribution can be described as follows:

$$
P\left(X_{1}, X_{2}, \ldots, X_{n}\right)=\prod_{i=1}^{n} P\left(X_{i} \mid X_{1}, X_{2}, \ldots, X_{i-1}\right)
$$

If the parent node set of $X_{i}$ is parent $\left(X_{i}\right)$, the probability of node $X_{i}$ is

$$
P\left(X_{i} \mid X_{1}, X_{2}, \ldots, X_{i-1}\right)=P\left(X_{i} \mid \operatorname{parent}\left(X_{i}\right)\right)
$$

The above equation can be simplified as follows:

$$
P\left(X_{1}, X_{2}, \ldots, X_{n}\right)=\prod_{i=1}^{n} P\left(X_{i} \mid \operatorname{parent}\left(X_{i}\right)\right)
$$

In the inverse reasoning, the Bayesian formula is used as the algorithm basis of the Bayesian network. The posterior probability is deduced by the prior probabilities of the influencing factors to analyse the influence degree of the factors, and the main factors for the quality control of fresh food in the $\mathrm{O} 2 \mathrm{O}$ mode are obtained. The Bayesian formula is expressed as follows:

Suppose that the sample space for experiment $E$ is $\Omega$ and that the events $A_{1}, A_{2}, \ldots, A_{n}$ are mutually incompatible. $A_{1}, A_{2}, \ldots, A_{n}$ form a complete event group, i.e., $\bigcup_{i=1}^{n} A_{i}=\Omega, A_{i} A_{j}=\emptyset, P\left(A_{i}\right)>0$, according to the multiplication theorem and conditional probability:

$$
P\left(A_{i} \mid B\right)=\frac{P\left(B \mid A_{i}\right) P\left(A_{i}\right)}{\sum_{i=1}^{n} P\left(B \mid A_{i}\right) P\left(A_{i}\right)}
$$

where $P\left(A_{i}\right)$ is the prior probability and $P\left(A_{i} \mid B\right)$ represents the posterior probability [13] The determination of conditional probabilities is the premise and basis of Bayesian network reasoning, the set of parent nodes of node $X_{i}$ is $U\left(X_{i}\right)=U_{1}, U_{2}, \ldots, U_{m}, x_{i}$ is the value of $X_{i}, U_{i}$ is the vector of the parent node variables, and $u_{i}$ is the value of vector $U_{i}$. The conditional probability of node $X_{i}$ is

$$
P\left(X_{i} \mid U\left(X_{i}\right)\right)=\frac{P\left(X_{i}, U\left(X_{i}\right)\right)}{P\left(U\left(X_{i}\right)\right)}=\frac{P\left(X_{i}=x_{i}, U_{i}=u_{i}\right)}{P\left(U_{i}=u_{i}\right)}
$$

For node $X_{i}$ with three parent nodes, the conditional probability is calculated as follows. When the parent node is in State0, the conditional probability value that node $X_{i}$ is in State0 is 


$$
\begin{aligned}
& P\left(X_{i}=\text { State } 0 \mid U_{1}=\text { State } 0, U_{2}=\text { State } 0, U_{3}=\text { State } 0\right)= \\
& \frac{P\left(X_{i}=\text { State } 0, U_{1}=\text { State } 0, U_{2}=\text { State } 0, U_{3}=\text { State } 0\right)}{P\left(U_{1}=\text { State } 0, U_{2}=\text { State } 0, U_{3}=\text { State } 0\right)}
\end{aligned}
$$

where the parameter State0 indicates the state of the node, and its specific meaning can be described as the poor or good condition of the event. The above formulas show that the calculation of conditional probability requires a large amount of sample data to satisfy different valued requirements of each node. The amount of calculation increases with the increase in number of parent nodes. In the absence of an accurate probability, the concept of group decision making is required based on expert experience; i.e., experts are consulted on the conditional probability of the nodes with the use of questionnaires and triangular fuzzy number for related data processing.

The IPCC (Intergovernmental Panel on Climate Change) uses the language variables of the occurrence probability with seven-stage classification to describe the probability values. The language variables and their corresponding probability values and triangular fuzzy numbers are shown in Table 2 .

Table 2: The semantic value of event probability and the corresponding triangular fuzzy number

\begin{tabular}{clc}
\hline Probability range & Triangular fuzzy number & Expression statements \\
\hline$<1 \%$ & $((0.0,0.0,0.1)$ & Very low \\
$1 \%-10 \%$ & $(0.0,0.1,0.3)$ & Low \\
$10 \%-33 \%$ & $(0.1,0.3,0.5)$ & A little low \\
$33 \%-66 \%$ & $(0.3,0.5,0.7)$ & Moderate \\
$66 \%-90 \%$ & $(0.5,0.7,0.9)$ & A little high \\
$90 \%-90 \%$ & $(0.7,0.9,1.0)$ & High \\
$>99 \%$ & $(0.9,1.0,1.0)$ & Very high \\
\hline
\end{tabular}

With the questionnaire survey method, the probability table of each node is obtained. If the number of experts is $q$, the probability of node $X_{i}$ in state $j$ given by the expert $k$ is converted into a triangular fuzzy number according to the above table

$$
\widetilde{P}_{i j}^{k}=\left(a_{i j}^{k}, m_{i j}^{k}, b_{i j}^{k}\right)_{(k=1,2, \ldots, q)}
$$

To obtain a relatively reasonable fuzzy probability based on the opinions of several experts, the average fuzzy probability of node $X_{i}$ in state $j$ is

$$
\widetilde{P}_{i j}^{\prime}=\frac{\widetilde{P}_{i j}^{1} \oplus \widetilde{P}_{i j}^{2} \oplus \ldots \oplus \widetilde{P}_{i j}^{q}}{q}=\left(a_{i j}^{\prime}, m_{i j}^{\prime}, b_{i j}^{\prime}\right)
$$

The fuzzy probability is transformed into the exact probability by using the mean area method. The exact probability of $\mathrm{g}$ in node $X_{i}$ in state $j$ is

$$
P_{i j}^{\prime}=\frac{a_{i j}^{\prime}+2 m_{i j}^{\prime}+b_{i j}^{\prime}}{4}
$$

To satisfy the requirements that the total probability of each node in different states is 1 , it is necessary to "normalize" the exact probability of each node in each state. After normalization, the exact probability of node $X_{i}$ in state $j$ is

$$
P_{i j}=\frac{P_{i j}^{\prime}}{\sum P_{i j}^{\prime}}
$$

Compared with the methods of Delphi method, fuzzy netural theory, risk-return model and fuzzy comprehensive evaluation, the fuzzy Bayesian network is a combination of the Bayesian method, the triangular fuzzy number and graph theory, combining prior knowledge with the sample information. This approach can address incomplete data and is an ideal model for data mining and uncertainty 
representation. First, because a large amount of sample data is obtained based on the experience of experts using the concept of group decision-making, in the case where accurate data cannot be obtained and the calculation process is complicated, the proposed model can convert uncertain data into triangular fuzzy numbers for specific processing, and the processing results are introduced into Bayesian networks. Then the Bayesian network quantitatively analyses the problem and qualitatively describes the causal relationship between the variables and their probability values. The fuzzy Bayesian network can conduct a reverse reasoning function to predict the key factors of certain links and the extent of the specific effects and use the posterior probability to find the key influencing factors.

\section{Simulation study}

GeNIe 2.0 used in this simulation (Graphical Network Interface) is a simulation software developed to build a graphical decision theory model. It has a visual interface and facilitates the construction and analysis of Bayesian network models. It can simultaneously conduct learning and reasoning about Bayesian networks, and support structure and parameter learning. The simulation environment can build complex Bayesian network models for large-scale nodes. The variables that need to be input are the prior probability value of each node and the conditional probability value of the non-root node. The output variables are the priori and posterior probability value of each node. The simulation process from the data to the model until the final result features less influence of the subjective method, simple operation process and high degree of visualization.

By analysing the supply parts in the $\mathrm{O} 2 \mathrm{O}$ mode, 46 factors influencing the quality control of fresh food in processes were determined and divided into 46 network nodes. The fresh food quality is measured as the final Bayesian network node. The number and range of the nodes in the Bayesian network are shown in Table 3.

In this paper, the Bayesian network structure is constructed manually based on expert knowledge. Then, the Bayesian network model is obtained through correction by analysing the database, as shown in Fig. 2.

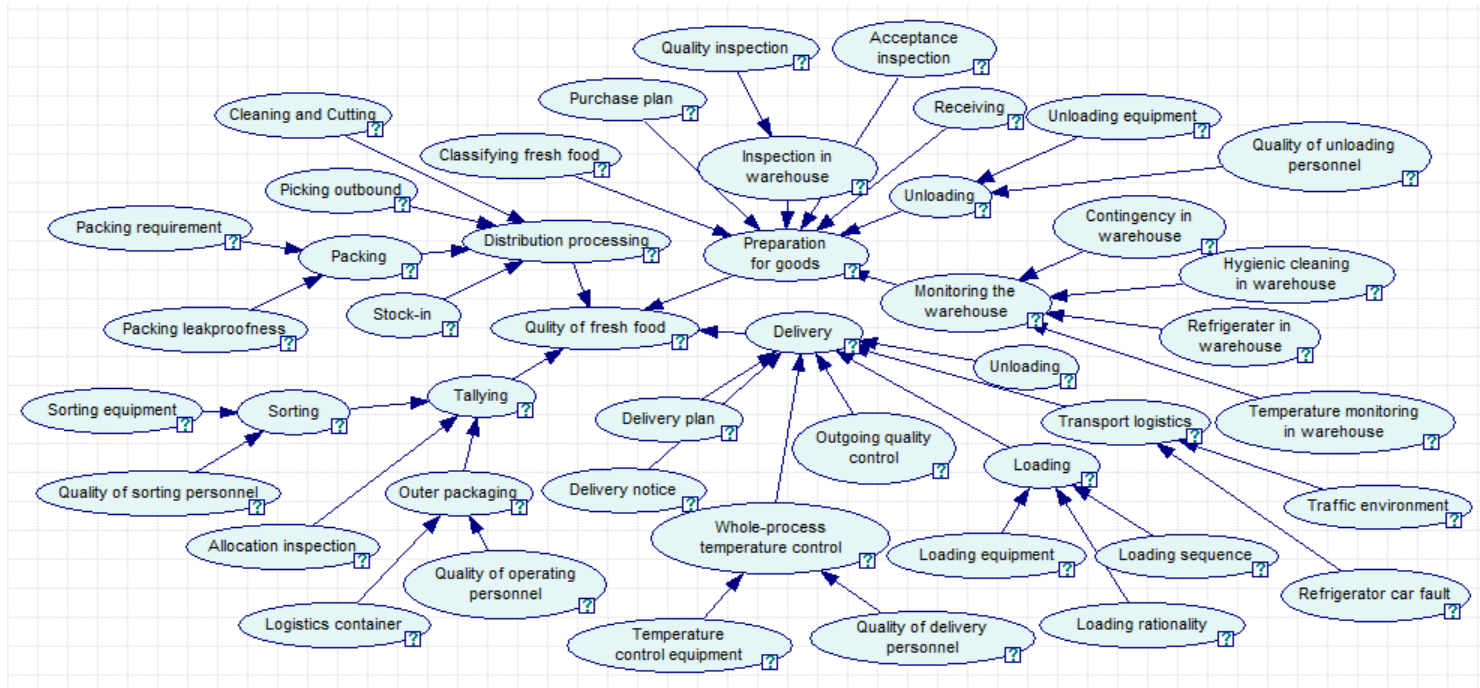

Figure 2: Bayesian network of fresh food quality

A complete fuzzy Bayesian network model contains the network topology and parameters of the model, and the model parameters refer to the probability distribution table of each node. After establishing the network topology, it is necessary to quantitatively describe the probability relations between the nodes, which is the basis of Bayesian network reasoning. Through the questionnaire survey and data processing of triangular fuzzy numbers, the appropriate conditional probability table is introduced for each node. An example of the conditional probability table of a node is shown in Table 4.

From the conditional probability table, we can clearly see the probability of node B10 in two states 
Table 3: Range of Bayesian networks

\begin{tabular}{|c|c|c|}
\hline Number & Node & Range \\
\hline $\mathrm{A}$ & Quality of fresh food & $(0,1)$ \\
\hline A1 & Preparation for goods & $(0,1)$ \\
\hline A2 & Distribution processing & $(0,1)$ \\
\hline A3 & Tallying & $(0,1)$ \\
\hline $\mathrm{A} 4$ & Delivery & $(0,1)$ \\
\hline B1 & Purchase plan & $(0,1)$ \\
\hline $\mathrm{B} 2$ & Acceptance inspection & $(0,1)$ \\
\hline B3 & Unloading & $(0,1)$ \\
\hline B4 & Receiving & $(0,1)$ \\
\hline B5 & Classifying fresh food & $(0,1)$ \\
\hline B6 & Inspection in warehouse & $(0,1)$ \\
\hline B7 & Monitoring the warehouse & $(0,1)$ \\
\hline B8 & Picking outbound & $(0,1)$ \\
\hline B9 & Cleaning and Cutting & $(0,1)$ \\
\hline B10 & Packing & $(0,1)$ \\
\hline B11 & Stock-in & $(0,1)$ \\
\hline B12 & Sorting & $(0,1)$ \\
\hline B13 & Allocation inspection & $(0,1)$ \\
\hline B14 & Outer packaging & $(0,1)$ \\
\hline B15 & Delivery plan & $(0,1)$ \\
\hline B16 & Delivery notice & $(0,1)$ \\
\hline B17 & Outgoing quality control & $(0,1)$ \\
\hline B18 & Loading & $(0,1)$ \\
\hline B19 & Transport logistics & $(0,1)$ \\
\hline $\mathrm{B} 20$ & Whole-process temperature control & $(0,1)$ \\
\hline B21 & Unloading & $(0,1)$ \\
\hline C1 & Unloading equipment & $(0,1)$ \\
\hline $\mathrm{C} 2$ & Quality of unloading personnel & $(0,1)$ \\
\hline C3 & Quality inspection & $(0,1)$ \\
\hline $\mathrm{C} 4$ & $\begin{array}{l}\text { Temperature monitoring in ware- } \\
\text { house }\end{array}$ & $(0,1)$ \\
\hline $\mathrm{C} 5$ & Hygienic cleaning in warehouse & $(0,1)$ \\
\hline C6 & Refrigerator in warehouse & $(0,1)$ \\
\hline $\mathrm{C} 7$ & Contingency in warehouse & $(0,1)$ \\
\hline $\mathrm{C} 8$ & Packing requirement & $(0,1)$ \\
\hline $\mathrm{C} 9$ & Packing leakproofness & $(0,1)$ \\
\hline $\mathrm{C} 10$ & Sorting equipment & $(0,1)$ \\
\hline $\mathrm{C} 11$ & Quality of sorting personnel & $(0,1)$ \\
\hline $\mathrm{C} 12$ & Logistics container & $(0,1)$ \\
\hline $\mathrm{C} 13$ & Quality of operating personnel & $(0,1)$ \\
\hline $\mathrm{C} 14$ & Loading equipment & $(0,1)$ \\
\hline $\mathrm{C} 15$ & Loading rationality & $(0,1)$ \\
\hline $\mathrm{C} 16$ & Loading sequence & $(0,1)$ \\
\hline $\mathrm{C} 17$ & Refrigerator car fault & $(0,1)$ \\
\hline $\mathrm{C} 18$ & Traffic environment & $(0,1)$ \\
\hline C19 & Temperature control equipment & $(0,1)$ \\
\hline $\mathrm{C} 20$ & Quality of delivery personnel & $(0,1)$ \\
\hline
\end{tabular}


Table 4: Conditional probability table of the packing level

\begin{tabular}{|c|c|c|c|c|c|}
\hline \multicolumn{2}{|c|}{ Condition } & \multicolumn{2}{c|}{ Triangular fuzzy number } & \multicolumn{2}{c|}{ Probability } \\
\hline State0 & State1 & State0 & State1 & State0 & State1 \\
\hline C8, C9 & & $(0.57,0.77,0.93)$ & $(0.03,0.17,0.37)$ & 0.8 & 0.2 \\
\hline C8 & C9 & $(0.37,0.57,0.77)$ & $(0.23,0.43,0.63)$ & 0.57 & 0.43 \\
\hline C9 & C8 & $(0.43,0.63,0.83)$ & $(0.17,0.37,0.57)$ & 0.63 & 0.37 \\
\hline & C8, C9 & $(0.33,0.5,0.7)$ & $(0.23,0.43,0.63)$ & 0.54 & 0.46 \\
\hline
\end{tabular}

when parent nodes C8 and C9 are in different conditions. For example, when both C8 and C9 are in State0, the probability of B10 being in State0, which is defined as the better state in this paper, is $80 \%$. When C8 and C9 are in State1, the probability of B10 being in State1, which is defined as the poor state, is $54 \%$.

\section{Result and Discussion}

To reflect the factors influencing the quality control of fresh food and make an objective evaluation, this paper investigated businesses that have joined the $\mathrm{O} 2 \mathrm{O}$ fresh platform, such as JD, Excellent fresh on a daily basis, and SF-best, and we collected relevant data influencing the quality of fresh food according to expert opinions. The simulation was conducted when the data were input into the software GeNIe after the triangular fuzzy number processing. The simulation data come from reality, and the factors in the supply of fresh food under $\mathrm{O} 2 \mathrm{O}$ mode are truly reflected in the simulation environment. According to forward reasoning, we can draw the probability of each node. The probability of the "quality of fresh food" in State0 is $65 \%$, as shown in Fig. 3, where "State0" is the better state and "State1" is the poor state.

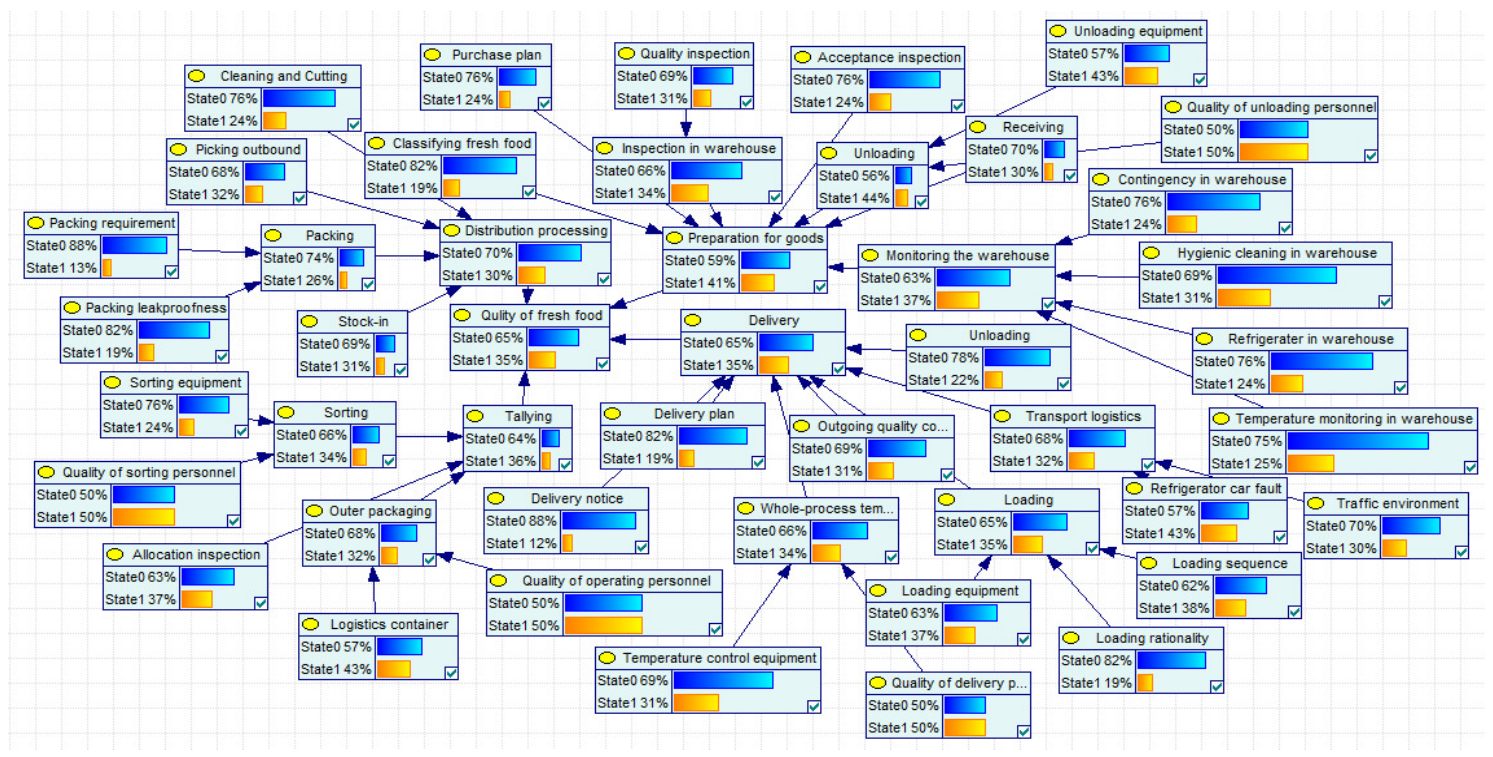

Figure 3: Prior probability model

Based on the inverse reasoning of the Bayesian network, when the quality of fresh food is poor, i.e., $P(A=$ State 1$)=1$, the link of goods preparation has the greatest impact on the quality safety, and the corresponding probability value is $56 \%$ according to the Bayes network simulation using GeNIe, followed by the delivery link, tallying link and circulation processing link. Consequently, the degree of impact on the quality and safety of fresh food is gradually weakened. In the link of goods preparation, unloading, inspection in warehouse, and monitoring the warehouse are the key factors for controlling the quality and safety of fresh food in the $\mathrm{O} 2 \mathrm{O}$ mode. The probability values showing the degree of influence are $44 \%, 37 \%$ and $34 \%$, as shown in Fig. 4. Therefore, the assurance of the quality and safety of fresh food should focus on the three aspects to strengthen implementation. 


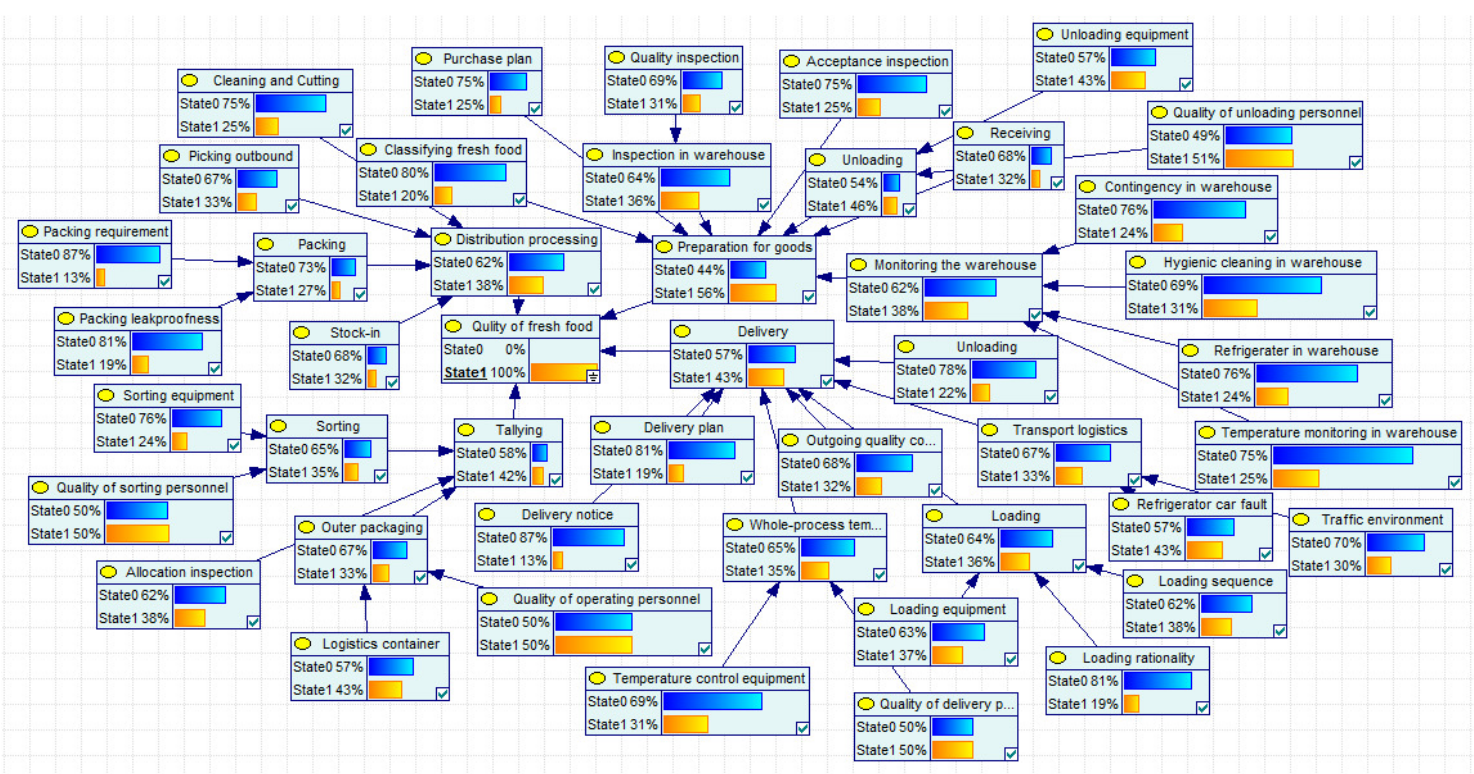

Figure 4: Posterior probability model

The research for the cold chain market shows that in the process of unloading operations, the probability that the packaged fresh food itself is damaged significantly increases. The use of automatic forklift and other operating equipment instead of traditional handling operations effectively reduces the rough work, shortens the exposure time at room temperature and improves the efficiency of unloading operations so that fresh food is well protected.

After the food enters the warehouse, strengthening the quality inspection provides a timely way to select the fresh food that has excessive pesticide residues, hormones and other chemical agents in order to prevent these unsafe fresh foods from entering the distribution channels, thus preventing serious harm with respect to fresh food quality and safety.

Effective warehouse monitoring operations can reduce the damage to the quality and safety of fresh food. First, powerful warehouse temperature monitoring can offer a suitable storage temperature to prevent fresh food from putrefaction. Second, timely cleaning of the warehouse prevents decayed food from breeding bacteria and from polluting the storage environment and stops the spreading of pests and harmful biological bacteria. In addition, the effective monitoring of cold storage equipment failure helps to improve the effect of fresh food refrigeration. Finally, strengthening monitoring for fire, theft and other accidents strongly protects the quality safety of fresh food in distribution centres.

\section{Conclusion}

Refining the factors influencing fresh food quality is an important measure for controlling quality safety. This paper fully integrates information on the supply process and considers the rule of e-commerce to introduce and perfect a series of evaluation indices considering the aspects of preparation, circulation, tally and delivery. Through the establishment of a Bayesian network and backward reasoning, the unloading level, warehouse inspection and warehouse monitoring are determined as the entry points for quality control, with corresponding degrees of influence of $44 \%, 37 \%$, and $34 \%$. The main points to protect the quality of food are introduced, which provides a theoretical basis for solving fresh food safety problems for business platforms.

In short, the methods and ideas adopted in this article have proposed a qualification standard for food circulation regulation in the $\mathrm{O} 2 \mathrm{O}$ model. In addition, the intelligent analysis of the indicator data solves the problem of information occlusion for downstream enterprises and customers and makes information in platforms more open. Consumers can reasonably select methods of procurement. This process integrates e-commerce platforms to provide products and control supervision.

There are still some improvements to be made in this paper. First, we only considered a single individual in the process of discussing the influencing factors of distribution. Further research can be 
extended to multiple distribution companies for joint distribution. Secondly, in the process of identifying factors that affect quality, the analysis of logistics supply chain is more about transportation, and improvement can also be considered from the supply chain itself.

\section{Acknowledgements}

This research was sponsored by a project of the National Key R\&D Program of China (2017YFC1600605), and a project of Beijing Philosophy and Social Science (17GLB013) and a project of Beijing Talents foundation of Organization Department of Beijing Municipal Committee of the CPC.

\section{Conflict of interest:}

The authors declare no conflict of interest.

\section{References}

[1] Anica-Popa, Ionut (2012). Architecture of an Inter-organizational Information System for Monitoring the Trace of Fresh Vegetables, Romanian Statistical Review, 60(X), 381-385, 2012.

[2] Aurelija, B. (2018). Dalia Romaskeviciene Online Shoppping and Consumer Protection, Journal of System and Management Sciences, 1, 1-22, 2018.

[3] Battini, D.; Calzavara, M.; Persona, A. et al. (2016). Sustainable Packaging Development for Fresh Food Supply Chains, Packaging Technology \& Science, 29(1), 25-43, 2016.

[4] Belc, N.; Duta, D., E.; Iorga, E. et al. (2016). Food Safety Aspects Concerning Traditional Foods, Emerging and Traditional Technologies for Safe, Healthy and Quality Food, 33-54, 2016.

[5] Cardamone, C.; Aleo, A.; Mammina, C. et al. (2015). Assessment of the microbiological quality of fresh produce on sale in Sicily, Italy: preliminary results, Journal of Biological ResearchThessaloniki, 22(1), 1-6, 2015.

[6] Cheung, T.C.; Cheng, E.C.C.; Chan, H.Y. (2015). Development of a Validated Database for the Authentication of Fresh/Chilled and Frozen Pork Using beta-Hydroxylacyl-CoA-Dehydrogenases (HADH) Assay, International Journal of Properties, 18(1), 73-80, 2015.

[7] Choi, J.; Norwood, H.; Seo, S. et al. (2016). Evaluation of food safety related behaviors of retail and food service employees while handling fresh and fresh-cut leafy greens, Food Control, 67, 199-208,2016.

[8] Davidson, V.J.; Ryks, J.; Fazil A.(2006). Fuzzy risk assessment tool for microbial hazards in food system, Fuzzy Sets \& Systems, 157(9), 1201-1210, 2006.

[9] Dong, Q.L.; Wang, H.M.; Pradeep, K.; Malakar, et al. (2015). Review of Progress in Quantitative Microbiological Risk Assessment in China, Food Science, 36(11), 221-229, 2015.

[10] Dzitac, I.; Filip, F.G.; Manolescu, M.J. (2017). Fuzzy Logic Is Not Fuzzy: World-renowned Computer Scientist Lofti A. Zadeh, International Journal of Computers Communications \& Control, 12(6), 748-789, 2017.

[11] Fadwa, C.; Vida, D. (2017). Electronic Media as Important Tool in Today's Business, Journal of Logistics, Informatics and Service Science, 4(2), 16-30, 2017.

[12] Gao, H.Y.; Chen, H.J.; Mu, H.L. et al. (2015). Research Advances of Fresh Food Packaging Materials, Journal of Chinese Institute of Food Science \& Technology, 15(10), 1-10, 2015. 
[13] Gong, J.; Caldas, C.H.; Gordon, C. (2011). Learning and classifying actions of construction workers and equipment using Bag-of-Video-Feature-Words and Bayesian network models, Advanced Engineering Informatics, 25(4), 771-782, 2011.

[14] Guo, J.Q.; Wang, X.Y.; Fan, S.Y. et al. (2017). Forward and reverse logistics network and route planning under the environment of low-carbon emissions: A case study of Shanghai fresh food E-commerce enterprises, Computers $\& 3$ Industrial Engineering, 106(C), 351-360, 2017.

[15] Higuchi, T.; Kuramochi, Y.; Saito, T.et al. (2012). Investigation of non-heating sterilization method of packed fresh foods by pulsed electric field, Power Modulator and High Voltage Conference, IEEE, 427-43, 2012.

[16] Hsu, C.I.; Chen, W.T. (2014). Optimizing fleet size and delivery scheduling for multi-temperature food distribution, Applied Mathematical Modelling, 38(3), 1077-1091. 2014.

[17] Kaale, L.D.; Eikevik, T.M.; Rustad, T. et al. (2011). Superchilling of food: A review, Journal of Food Engineering, 107(2), 141-146, 2011.

[18] Kaipia, R.; Dukovska-Popovska, I.; Loikkanen, L. (2013). Creating sustainable fresh food supply chains through waste reduction, International Journal of Physical Distribution $\&$ Logistics Management, 43(3), 262-276, 2013.

[19] Lee, S.Y.; Lee, S.J.; Choi, D.S. et al. (2015). Current topics in active and intelligent food packaging for preservation of fresh foods, Journal of the Science of Food 63 Agriculture, 95(14), 2799, 2015.

[20] Manos, B.; Manikas, I. (2010). Traceability in the Greek fresh produce sector: drivers and constraints, British Food Journal, 112(6), 640-652, 2010.

[21] Martinezsimarro, D.; Sanchez, J.M.P.; Vela, R.A.(2010). Gaps to Fill Between Theoretical Interoperable Quality and Food Safety Environment and Enterprise Implementations, Springer London, 377-385, 2010.

[22] Singh, A.; Shukla, N.; Mishra, N. (2018). Social media data analytics to improve supply chain management in food industries, Transportation Research Part E: Logistics and Transportation Review, 114, 398-415, 2018.

[23] Soon, J.M.; Davies, W.P.;Chadd, S.A. et al. (2013). Field application of farm-food safety risk assessment (FRAMp) tool for small and medium fresh produce farms, Food Chemistry, 136(3-4), 1603-1609, 2013.

[24] Soto-Silva, W.E.; Gonzalez -araya, M.C.; Oliva-Fernandez, M.A. et al. (2017). Optimizing fresh food logistics for processing: Application for a large Chilean apple supply chain, Computers $\&$ Electronics in Agriculture, 136, 42-57, 2017.

[25] Stonehouse, G.G.; Evans, J.A. (2015). The use of supercooling for fresh foods: A review, Journal of Food Engineering, 148, 74-79, 2015

[26] Wang, J.; Yue, H.L.; Zhou, Z.N. (2017). An Improved Traceability System for Food Quality Assurance and Evaluation Based on Fuzzy Classification and Neural Network, Food Control, 79, 363-370, 2017.

[27] Wu, X.; Nie, L.; Xu, M.; Yan, F. (2018). A perishable food supply chain problem considering demand uncertainty and time deadline constraints: Modeling and application to a high-speed railway catering service, Transportation Research Part E: Logistics and Transportation Review, 111, 186-209, 2018.

[28] Xu,W.; Liu,L.N.; Zhang,Q.S.; Liu,P. (2018). Location decision-making of equipment manufacturing enterprise under dual channel purchase and sale mode, Complexity, 1-16, 2018. 
[29] Xu,W.;Yin,Y.(2018). Functional objectives decision-making of discrete manufacturing system based on integrated ant colony optimization and particle swarm optimization approach, Advances in Production Engineering \& Management, 13(4), 389-404, 2018.

[30] Yang, L.; Tang, R.H. (2019). Comparisons of sales modes for a fresh product supply chain with freshness-keeping effort, Transportation Research Part E: Logistics and Transportation Review, $125,425-448,2019$.

[31] Zhang, H; Xiong, Y; He, M.K.; Qu, C. (2017). Location Model for Distribution Centers for Fulfilling Electronic Orders of Fresh Foods under Uncertain Demand, Scientific Programming, 2017.

[32] Zhang, M.; Tang, X.C.; Pu, M.Z. et al.(2014). Co-regulation in Food Safety Governance: Enterprises, Government and the Third Party, Food Science, 35(13), 286-292, 2014.

[33] Zhang, M.; Meng, X.; Bhandari, B. et al. (2016). Recent Developments in Film and Gas Research in Modified Atmosphere Packaging of Fresh Foods, Critical Reviews in Food Science 83 Nutrition, 56(13), 2174, 2016.

[34] Zhou, J.; Sun, J. (2015). Strategy Research on Perfecting the Cold-chain Logistics System of Fresh Food, 2015 International Conference on Education Technology, Management and Humanities Science (ETMHS 2015), 2015.

[35] Zou, Y.F.; Xie, R.H.(2012). Study on Order Policies of Fresh Food Base on Safety Reliability, Advanced Materials Research, 452, 853-857, 2012.

\section{c) (7) (9)}

Copyright (C) 2020 by the authors. Licensee Agora University, Oradea, Romania.

This is an open access article distributed under the terms and conditions of the Creative Commons Attribution-NonCommercial 4.0 International License.

Journal's webpage: http://univagora.ro/jour/index.php/ijccc/

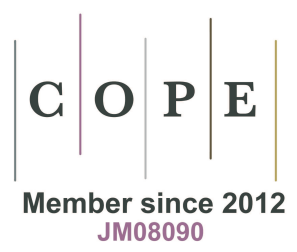

This journal is a member of, and subscribes to the principles of, the Committee on Publication Ethics (COPE).

https://publicationethics.org/members/international-journal-computers-communications-and-control

Cite this paper as:

Zhang, H.; Feng, H.; Cui, Y.; Wang, Y. (2020). A Fuzzy Bayesian Network Model for Quality Control in $\mathrm{O} 2 \mathrm{O}$ e-Commerce, International Journal of Computers Communications \& Control, 15(1), 1003, 2020. https://doi.org/10.15837/ijccc.2020.1.3783 